\title{
Vegetation Needs and Concerns in Urban Areas*
}

\author{
Erik Jorgensen \\ Forest Management Institute \\ Ottawa, Ontario
}

\section{Introduction}

A new government approach to the planning of the urban environment has evolved during the past few years. Emphasis has increasingly been placed on quality rather than quantity. The socioeconomic and environmental situations of city dwellers, rather than solely the spatial arrangement of man-made structures, have come to the forefront. The management of services and the interaction between services, rather than the mere investment in physical structures, have come into focus. These changes have led to a more complex public participation mechanism in our society and generate an increasing demand for information from the varied professions concerned with specific elements of the urban makeup. The major urban planning concerns can be summarized as:

1. Housing - concern for amenities and indoor as well as outdoor space.

2. Services and Employment - concerns for health, education and recreational services.

3. Natural Environment - concerns for air and water quality, exposure to noise and natural disasters, better conditions and land quality.

4. Social and Cultural - concerns for the preservation of typical urban landscape as part of the national heritage.

Urban forestry has input in all four concerns. It deals with the management of vegetation within the urban area and for the urban population. Urban forestry has been defined as: "A specialized branch of forestry which has as its objectives the cultivation and management of trees and forests for their present and potential contributions to the physiological, sociological and economic well-being of urban society." Expressed in another way, urban forestry can be seen as a medium for transfer of ecological forest management from the forestry setting to the urban environment for the benefit of this and future generations. The term as used here includes all areas in Canada - cities, towns and villages with a minimum population of 1,000 people and a density above 1,000 people/ $/ \mathrm{mi}^{2}$. On the basis of this definition, Statistics Canada has forecast that approximatety $95 \%$ of Canada's total population will be living in urban settlements at the year 2000. According to the 1971 Canada Census, only $75 \%$ of the population lived in urban settlements.

*Reprinted with permission from Proc.

Workshop on Ecol. Land Class in Urban

Areas, Can. Comm. on Ecol. Land Class., Nov. 1976.

\section{Vegetation Functions in the Urban Environment}

Urban vegetation occurs in two different settings, namely the garden or horticultural habitat and the forest habitat, both having important environmental functions within the settlement area. Trees, because of their size and longevity, play a dominant role within both types of habitat. Looking at the functions of these two vegetation settings, we find that both offer recreational and aesthetic values important to health (physical and mental) and general well-being of residents, as well as environmental modifications. The main differences between the two settings are to be found in their management requirements, the size of land-use area required for their perpetuation and their environmental impact.

The Garden or Horticultural Habitat: This may vary in size from a small flower bed or rows of trees planted along sidewalks to large city parks requiring intensive (and costly) maintenance and management. The main benefits which urban man can derive from this habitat must be seen in the recreational and aesthetic values created, which are important for community health, and no doubt have an ameliorating effect on the environment of settlements. The intensive management of this habitat offers the homeowner an opportunity for physical outdoor activity, rare in today's television-oriented society, and for many, a source of regaining physical and mental health. The creation of private spaces and of an aesthetically pleasant community living environment is another important function.

The presence of the horticultural habitat within the human settlement has many modifying and ameliorating effects on the otherwise barren, manmade human settlement. It helps to conserve energy consumption by modifying temperature and humidity changes. It facilitates recharging of groundwater within built-up areas and the control of soil erosion by runoff. The vegetation also reduces sound and air pollution by serving as a pollution sink. Further, the vegetation makes possible contacts between man and a significant portion of the area's natural wildlife population.

There can also be detrimental vegetation effects to society. Clogging of drains and problems related to the location of aerial and underground service lines are well known. Moreover, trees in some areas of the country contribute to the destruction of building foundations. Some plant species are highly toxic to animals and human beings, 
and some cause allergies. Certain plant societies may also attract unwanted wildlife species close to human habitation.

The Forest Habitat: The importance of the Canadian forest to society is steadily growing. In addition to its obvious socioeconomic function, more attention is recently being paid to other functions of the forest such as water management, recreation and conservation of soil, plants and wildlife. Despite this, the role of the forest as an integrated part of our settlement area deserves additional considerations before the ideal living environment can be created for Canadians.

Although the minimum size of a forest ecosystem capable of being managed in perpetuity has not been scientifically established in Canada as such, 50 to 100 ha may be the minimum area required, depending on the forest region. A forest of such a size or larger in the periphery of or within the settled area serves many functions. The first of these is 'renaturalizing', the renovation and reinforcement of natural elements in the built-up landscape. The forest can enhance the biotic value and eliminate the unfavourable influences of technical intervention within the settlement area. The forest ameliorates the climate to a higher degree than other urban vegetation by minimizing temperature and humidity fluctuations and by lowering the wind speed. It can conserve watersheds and their continued production of clean water for human consumption. Further, the forest ecosystem provides an outstanding function in the sanitation of air and water. It provides habitat for wildlife which in turn aids in the control of noxious insects and rodents. The forest has a high capacity for recycling organic human wastes and for the control of pathogenic organisms. It cannot, however, be expected to recycle larger amounts of industrial wastes which, in a sense, constitute a resource waste, often of a nonrenewable resource, a problem which can best be resolved in a modification of the manufacturing process.

Another important function of the forest within the settlement area is that of creating the basis for a stable settlement environment. The rapidly changing modern technology has led to a built-in obsolescence in most man-made structures which in turn, has created an ever-changing cityscape. The use of permanently forested areas for separation of different functional areas within the settlement could conceivably aid in the recreation of a stable urban-dwelling environment. The forest could thus separate the working and transport areas from the residential areas and other areas with different urban qualities. If the forest were used in this manner it would create readily accessible areas for recreation, whether the object of the recreation was the forest itself and its ecosystem or whether the forest merely served as a setting for a non-forest-related recreational activity.

A third major function of forests within settlement areas may be referred to as the 'educational function'. The ecological input in the educational program for Canadians must be at par with that of arts and technology. This goal requires ready and regular access to the forest environment which offers the foremost demonstration of nature's intricate laws. The achievement of a generally high level of understanding of ecology is of prime interest, not least in Canada, which through history and to the present day has benefited greatly from its major natural renewable resource, the forest. Without such an ecological understanding, a proper forest management policy for Canada cannot be expected to be established for the benefit of future generations of Canadians.

In addition to these three major functions of an urban forest, we should remember that a properly managed forest can also be an economic resource for the urban population, in that it can provide high quality raw products close to the market. Other functions of the forest, including those of the forest as a design and ornamental object, shall be left out of this discussion.

\section{Urban Vegetation Needs}

In summarizing the urban vegetation functions, the quality of services which can be achieved from urban vegetation and vegetation management has been sketched. What remains in the discussion of the needs is, therefore, a statement of quantity required, or to put it another way: How many hectares per square kilometre, or per 100,000 people, is the minimum base requirement for vegetation? Presently there is no basis for providing a figure as a guideline and it is believed that the answer will vary from location to location. Closeness to the ocean, other major water bodies, or mountains, as well as climate, are factors greatly influencing the vegetation needs of society. To this can be added the urban society standard with regard to 'living within one's natural environment'. From recent development and experimentation by the avant-garde urban planners, one may find the trend of the 60's (the space age) directed toward totally enclosed, climatically controlled living environments 'under the dome', the surface of the soil, or even under the oceans. I have little faith in these kinds of ideas as they, like our present 'disposable society', have a tendency to dehumanize society to a degree that I would hope not to experience. The vegetation needs for urban society must be determined by the philosophy guiding the establishment of an urban living policy for other developments such as nuclear power plants and hydroelectric dams, requiring major capital investments. Where the needs exist for a stable, perpetuating society, the needs for vegetation and trees will be established with little difficulty. What other living landscape element, but the tree, can form a link between the past and the present as well as a projection into the future?

\section{Urban Vegetation Concerns}

Our concerns regarding existing vegetation in or outside the settlement area are many and 
varied. The conservation of valuable remnants of the natural forest and of urban horticultural plantings must be high on the list. Technology and public apathy both offer threats to this conservation project. The biggest threat is the lack of public understanding of the benefits which ecologically based management can offer. Only through management procedures is it possible to secure the continuous flow of benefits from the forest. Left alone, stagnation will occur in the forest; it will become even-aged, uniform and over-mature, waiting for a natural disaster (fire, insects or disease) for its rejuvenation. Management alone can secure an uneven-aged, healthy forest with a continuous flow of benefits.

Another concern relates to the permanency of land use required for forestry. Forests, and for that matter individual trees, require long-term unobstructed land tenure for their full development. It obviously takes 100 years of growing to get a 100-year-old tree - there are no instant trees! Further, these 'youngsters' who may serve for centuries into the future require space for both crown and root development. The competitive land prices and the requirements for service lines are major considerations in the dedication of lands for vegetation use on a long-term basis. However, the most recent trend in housing development is towards a self-contained unit which provides its own energy and water and waste treatment plants, thus only requiring access roads as a service. This is a development of much promise for urban trees and forests of the future.

The selection and availability of tree species for planting is most important and particularly under Canadian conditions. First, there is the problem of obtaining hardy tree species well suited to specific localities. In the nursery industry, there is presently little understanding of the requirements to meet this goal. All our native tree species cover large areas with varied climatic and edaphic conditions which have led to the development of great ecological variance within the species. Yet, nursery catalogues still classify tree species according to hardiness zones and offer no information relating to provenance or seed origin. Secondly, there is the question of where and how exotic species should be used. Our present city vegetation is to a high degree dominated by what we may call an 'international tree cover', where Asiatic and European species dominate over native species. This is not solely a Canadian condition. It is common throughout the western world. It should, however, be of special concern when we also meet these same exotic trees along our highways with a backdrop of native trees, and it may even affect future tourism. Much of the value of the cityscapes is related to the nature of the architecture and the surrounding vegetation. In recent years this architecture has become international, and if we also make and perpetuate the international vegetation used for its landscaping, there will then be very little point in moving from one city to another as a tourist.
The health of city trees under present conditions is a major concern. The most widely distributed cause for decline is the lack of proper space allocation for trees in strees planning. Street trees are continuously abused by construction and by road salt, leading to total or partial loss of vegetation which should have served for years to come. Because of the growing conditions, urban trees are also particularly susceptible to attack by otherwise minor pests and disease-causing organisms. Finally, there is the threat of introduced diseases like the Dutch elm disease which has upset the cityscape. A large part of the health problem can no doubt be solved through a change in urban planning, allowing sufficient soil support systems for the root and space for the crown. As a guard against new, introduced, strongly pathogenic diseases and insect pests, a species and genetic variation should be introduced in the urban planning program, as a matter of practice. Only through assuring the widest possible variation will it be possible to guard against future major upsets of the vegetation cityscape.

Trees and other vegetation have, through the times, offered cover and protection for peaceful members of society as well as for the criminal elements. Many people are interested in the relationship between crime and vegetation. In a recent public speech in the U.S., a well-meaning lady suggested the planting of trees in inner city slums would reduce the crime rate. Others have claimed that no vegetation and plenty of light reduces crime. My concern is that this topic is being discussed seriously at all. In my view, crime and slums must be related to human and society shortcomings, rather than to vegetation which by no means is the only cover available to criminals within the cityscape.

One should not underestimate the value of vegetation as a source for local pride. It is this type of pride and the feeling of belonging it creates that, in turn, forms the basis for community existence and is at the root of nationhood.

Another concern related to urban vegetation planning and management is the need for continued and expanded research vis-à-vis the ecologically based management of urban vegetation. This type of research requires the education of researchers who can continue to further develop, in a pragmatically oriented manner, the much needed information gathering and interpretation. It also requires that society be willing to fund this type of activity, both within and outside the government sphere. A first step in achieving this needed support must be obtaining the support of the professions involved in urban planning and government. The second, and not lesser important step, is to back the work with public support.

\section{Conclusion}

From the review of vegetation functions, needs, and concerns expressed herein, it can be conceived that urban vegetation has a great significance for society as a whole, especially in Canada 
with an ever increasing rate of urbanization. Problems relating to urban vegetation deserve much greater attention from professionals than has been the case in the past. Foresters, horticulturists, agriculturists, architects, medical doctors, ecologists, geographers and social scientists all have to provide input before the ideal urban vegetation can be created within the Canadian settlements. What is needed for the creation of a proper, ecologically based, urban forest management is a truly interdisciplinary team effort.

\section{Bibliography}

Andresen, John W. 1974. Community and urban forestry A selcted and annotated bibliography. Southeast. Area, State and Private For., U.S. For. Serv., Ga.

Anon. 1971. Trees and forests in an urbanizing environment. Coop. Ext. Serv., Univ. Mass., U.S. Dep. Agric. and City Ext. Serv. Coop.
Jorgensen, E. 1967. Urban forestry: some problems and proposals. Prepared for Ninth Commw. For. Conf., 1978. Fac. For. Univ. Toronto, Toronto, Ont.

Jorgensen, E. 1970. Urban forestry in Canada. The Shade Tree Res. Lab., Fac. For., Univ. Toronto, Toronto, Ont.

Jorgensen, E. 1974. Towards an urban forestry concept. Tenth Commonw. For. Conf., Oxford, Engl.

Jorgensen, E. 1975. Urban arboriculture - the state of the art. Recreation Canada. Vol. 33.

MacNeill, J.W. 1971. Environmental management. Information Canada. Ottawa, Ont.

Richardson, S.P. 1972. Urban forestry - apartheid or integration. Comm., Seventh World For. Congr., Buenos Aires, Argent.

Smith, J.H.G. and G. Lessard. 1970. Forest resources research in Canada. Background Study, Sci. Counc. Can. Spec. Study No. 14. Inf. Can., Ottawa, Ont.

Sopper, W.E., and L.T. Kardos. 1973. Recycling treated municipal wastewater and sludge through forest and cropland. Penn. State Univ. Press, Univ. Park and Lond.

Zachar, D. 1975. The forest as a component of settlement. Ekistics 235:66-67.

\section{FORESTRY STUDENTS, DON'T OVERLOOK THIS BENEFIT FROM YOUR CIF MEMBERSHIP}

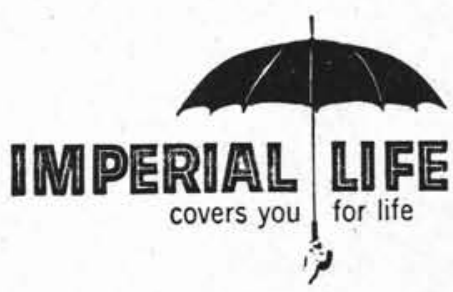

One of the many benefits from your membership in the Canadian Institute of Forestry is low cost life insurance. For example, you can obtain units of $\$ 10,000$ of protection for just $\$ 20$ a year (up to age 30 ) . . . and you may obtain as much as $\$ 100,000$ at this low rate.

A really special opportunity to start building your life insurance program . . . to protect those who may depend on you . . . to develop a widely acceptable form of collateral in case you may have to borrow in the future.

The plan is administered by The Imperial life Assurance Company of Canada and you may obtain details by writing to the Canadian Institute of Forestry, Box 5000, Macdonald College, P.Q. HOA 1CO. Absolutely no obligation. 